A. Sánchez-Villegas

J. A. Martínez

J. De Irala

M. A. Martínez-González

and members of the SUN research group

\title{
Determinants of the adherence to an "a priori" defined Mediterranean dietary pattern
}

\author{
Financial support \\ Grant from the Department of Health of the \\ Navarra Regional Government (Project \\ 36/2001) \\ Grant from FIS (Fondo de Investiga- \\ ciones Sanitarias) of the Spanish Ministry \\ of Health (Project 01/0619)
}

\section{Summary Background A} prospective cohort study with university level participants was initiated to study the effect of Mediterranean diet on health. Aims The objective of this study was to identify possible lifestyle and socioeconomic variables associated with the consumption of a Mediterranean dietary pattern (MDP). Method: This analysis includes 1587 males and 2260 females. MDP was defined "a priori" by summing the standardized residuals of nutrients and foods after adjusting a regression model using total energy intake as the independent variable. Multiple regression and non-parametric locally weighted regression models were adjusted with the rela- tive adherence to the MDP as the dependent variable in males and females. Results Women were more compliant than men with the MDP (Coefficient regression $(\mathrm{b})=4.1$; Confidence Interval (CI) $95 \%=3.2$ to 4.9). The compliance with the MDP was significantly poorer among younger participants both in men and women $(\mathrm{p}<0.001$ in men and in women). Participants who were more physically active were more likely to fulfill the traditional MDP ( $\mathrm{p}=0.01$ in men and $\mathrm{p}<0.001$ in women). Conclusions Our findings provide evidence supporting the progressive departure from the traditional MDP in younger and highly educated subjects of the Mediterranean area. A more active life-style is associated with a better compliance with the MDP.

Key words eating patterns Mediterranean dietary pattern confounders

\section{Introduction}

The concept of Mediterranean diet was developed by Keys and Grande in the 1950s to describe food habits observed in the Mediterranean area [1]. The concept of Mediterranean diet has further been referred to as the traditional dietary pattern found in the olive-growing areas around the Mediterranean (mainly Crete, Greece and southern Italy) in the late 1950s and early 1960s [2]. There are variations of this type of diet in other regions of Italy, in Albany, Spain, France, Lebanon, Morocco, Portugal, Syria, Tunisia and Turkey [3]. Although different regions are characterized by their own diet it can be assumed that these diets are variations of the same identity, the Mediterranean dietary pattern (MDP). For example, the Italian variety has a high consumption of pasta, whereas fish consumption is relatively high in Spain. 
There are common features in the MDP such as the abundant consumption of plant foods (vegetables, potatoes, legumes, nuts and cereals like pasta, bread and rice). Furthermore, fresh and varied fruits are the main and the common dessert and olive oil is the main source of fat, which is used both in salads and for cooking. Other representative features are the frequent consumption of fish; moderate, but consistent wine consumption with meals; relatively low amounts of meat (mainly poultry, instead of beef and pork) and low to moderate consumption of dairy products.

In nutritional epidemiology, analyses of individual nutrients and food can ignore important potential interactions between components of a diet. For this reason, there is an increasing interest in the study of dietary patterns because people do not eat isolated nutrients [4]. The MDP could offer an interesting alternative in health promotion because this pattern has been postulated as being protective against coronary heart disease (CHD) $[5,6]$. The similarity of several risk factors and empirical and mechanistic evidence, support the hypothesis that some aspects of the MDP could also contribute to protect against the occurrence of diabetes mellitus type 2 [7], hypertension [8], stroke [9] and even against osteoporosis [10]. Some available evidence also suggests a beneficial effect in some types of cancer [11,12].

The SUN (Seguimiento Universidad de Navarra) (The University of Navarra follow-up Study) Project is a prospective cohort study based on a cohort of alumni of the University of Navarra that has been recently launched to assess the protective role of the MDP on $\mathrm{CHD}$. The objective of this analysis was to identify the variables cross-sectionally associated with the MDP in the baseline assessment of the cohort.

\section{Methods}

This study is a cross-sectional analysis of the baseline data of a prospective cohort study based on self-reported questionnaires. The follow-up questionnaires will be sent to alumni of the University of Navarra every two years. The project was designed in collaboration with the Harvard School of Public Health during 1998 and the methodology is similar to that used in large American cohorts such as the Nurses Health Study and the Health Professionals Follow-up Study.

Dietary and non-dietary exposures were measured by two mailed questionnaires (baseline questionnaires). One of them was a self-administered questionnaire related to life-styles and the other one was a semiquantitative food frequency questionnaire. The life-style questionnaire included 46 items for men and 54 items for women. This questionnaire included sociodemographic (sex, age, marital status, university degree or employment), anthropometric (weight, height, body image or weight change), health-related habits (smoking status, alcohol consumption, use of seatbelt, use of sun cream or physical activity) and medical history variables (use of medication, cholesterol level, blood pressure or family history of several diseases). The semi-quantitative food frequency questionnaire was developed and validated by Martín-Moreno et al. [13]. It is similar and based on a previous food-frequency questionnaire which was developed, tested, and refined by the Department of Nutrition of the Harvard School of Public Health over the past twenty years [14].

Project feasibility was tested with a pilot study developed in two waves during 1999. Participant recruitment started in January 2000.

To date, an invitational letter has been sent to more than 50,000 potential participants. The data base of the SUN Project incorporated 4,259 participants as of March 2001. Participants recruitment continues to date, and approximately 13,000 participants have already completed the baseline questionnaire (August 2002). However, we considered that a sample size of 4,259 participants was sufficient to obtain adequate statistical power to assess the main factors associated with the adherence to a MDP.

Nutrient intake scores were computed using an ad hoc computer program specifically developed for this aim. A dietitian updated the nutrient data bank using the latest available information included in the food composition tables for Spain [15, 16]. Nutrient scores were calculated as frequency $x$ nutrient composition of specified portion size where frequencies were measured in nine frequency categories $(6+$ per day $/ 4-6$ per day/2-3 per day/1 per day/5-6 per week/2-4 per week/1 per week/1-3 per month/never or almost never for each food item.

There were 385 individuals who reported excessively high (more than $4200 \mathrm{Kcal} /$ day in men and 3500 $\mathrm{Kcal} /$ day in women) or excessively low values (less than $800 \mathrm{Kcal} /$ day in men and $600 \mathrm{Kcal} /$ day in women) for total food or energy intake. In addition, 27 individuals had missing data for some of the variables used in the analyses. Therefore, 1,587 men and 2,260 women were included in the analyses (412 exclusions).

The MDP was defined according to an "a priori" defined overall score previously defined and used in the scientific literature [17-19]. It was computed by the following steps:

- First, an energy-adjusted value was obtained for each individual for the daily consumption of legumes, cereals (including bread and potatoes), fruit, vegetables, meat (including meat products), and milk (including dairy products) [20].

- Second, the adjusted intake of each of these food groups was standardized as a $\mathrm{z}$ value (observedmean/standard deviation). For example, if the mean observed value for energy-adjusted consumption of 
vegetables was $180 \mathrm{~g} / \mathrm{day}$, and the standard deviation was $140 \mathrm{~g} /$ day, an individual consuming $200 \mathrm{~g} /$ day would have a value of $\mathrm{z}=((200-180) / 140)=0.14$.

- Third, for scoring "moderate" alcohol consumption, a transformation centered at the level of consuming $30 \mathrm{~g} /$ day for men $(30$ - |30-absolute alcohol intake $\mid)$, and $20 \mathrm{~g}$ /day for women (20 - $\mid 20$-absolute alcohol intake|) was used to obtain the highest value for men consuming $30 \mathrm{~g} /$ day or women consuming $20 \mathrm{~g} /$ day, and progressive lower values as the consumption was lower or higher than these values. These values of intake (30 g/day for men and $20 \mathrm{~g} /$ day for women) were associated with the lowest CHD risks in the Nurses Health Study [21] and in the Health Professionals Follow-up Study [22]. The results of these transformations of alcohol intake were also standardized as $\mathrm{Z}$ values.

- Fourth, the ratio of monounsaturated to saturated fatty acids (MUFA/SFA) and the intake of trans-fatty acids (TRANS) was also directly standardized as a $\mathrm{z}$ value.

- Fifth, the total score for the MDP weighted favorably the consumption of legumes, cereals (including bread and potatoes), fruit and vegetables, moderate alcohol consumption and the MUFA/SFA ratio; and unfavorably the consumption of meat (and meat products) and milk (and dairy products) (Table 1).

$$
\begin{array}{r}
\sum Z_{i}=Z_{\text {legumes }}+Z_{\text {cereals }}+Z_{\text {fruit }}+Z_{\text {vegetables }}+Z_{\text {alcohol }}+ \\
Z_{M U F A / S F A}-Z_{\text {TRANS }}-Z_{\text {meat }}-Z_{\text {milk }}
\end{array}
$$

The MDP was converted to relative percentage of adherence using the range of values of the sample. A participant with a maximum value of adherence in the sample obtained $100 \%$ of adherence. A participant with a minimum value of adherence obtained $0 \%$ in the relative percentage.

Adherence $\left(\right.$ Percentage $\left._{i}\right)=\frac{\left(\sum Z_{i}-\sum Z_{\min }\right) \times 100}{\left(\sum Z_{\max }-\sum Z_{\min }\right)}$

Univariate and multivariate analyses were fitted to assess the relationship between several sociodemographic and life-style variables and the relative percentage of adherence to a MDP. The univariate analysis consisted of a Locally Weighted Regression Scatterplot Smoothing (LOWESS) to ascertain the association between different variables (age, body mass index, number of cigarettes, physical activity during leisure time, number of hours viewing television and number of hours taking a nap) and the relative adherence to a MDP. The LOWESS method is based on the weighted estimation of the coefficients of a linear regression according to the distance between each observation and the adjacent values. The percentage of adjacent observations used to estimate the coefficients ranged from $50 \%$ to $85 \%$ of all values [23].
Table 1 Distribution of sociodemographic and lifestyle variables across quintiles of the "a priori"

\begin{tabular}{|c|c|c|c|c|c|}
\hline & \multicolumn{5}{|c|}{ QUINTILE of the "a priori" defined MDP } \\
\hline & Q1 & Q2 & Q3 & Q4 & Q5 \\
\hline Age (years) [mean (SD)] & $35.2(9.8)$ & $37.3(10.2)$ & $39.5(11.5)$ & $42.1(11.4)$ & $46.1(13.0)$ \\
\hline $\begin{array}{l}\text { Physical activity during leisure } \\
\text { time in METs-hour/week } \\
\text { [mean (SD)] }\end{array}$ & $23.8(25.8)$ & $24.2(21.7)$ & $25.6(22.4)$ & $24.7(23.2)$ & $28.7(26.9)$ \\
\hline $\begin{array}{l}\text { Self-awareness of HDL-c } \\
\text { levels (\%) }\end{array}$ & 19.8 & 25.6 & 29.6 & 39.4 & 38.6 \\
\hline $\begin{array}{l}\text { Hours a week taking a nap } \\
\text { (siesta) [mean (SD)] }\end{array}$ & $1.9(2.4)$ & $2.1(2.4)$ & $2.2(2.3)$ & $2.7(2.7)$ & $2.8(2.8)$ \\
\hline \multicolumn{6}{|l|}{ Smoking (\%) } \\
\hline Ex-smokers & 18.1 & 26.7 & 26.6 & 33.1 & 34.1 \\
\hline Current smokers & 24.9 & 25.7 & 24.3 & 22.7 & 23.4 \\
\hline \multicolumn{6}{|l|}{$\begin{array}{l}\text { University degree completed } \\
\text { in college }(\%)^{*}\end{array}$} \\
\hline Medicine & 14.1 & 17.0 & 23.0 & 22.2 & 24.5 \\
\hline Pharmacy & 6.2 & 3.3 & 7.4 & 4.3 & 3.2 \\
\hline Biology & 5.2 & 7.2 & 5.0 & 6.8 & 4.3 \\
\hline Other degrees ${ }^{\mathrm{a}}$ & 73.8 & 72.1 & 63.9 & 66.3 & 67.2 \\
\hline
\end{tabular}
defined MDP in men
Q1-Q5 Quintiles values of adherence to the "a priori" defined MDP.

SD Standard Deviation

METs-hours/week Metabolic equivalents of energy expenditure in leisure time physical activities during one week.

HDLC High density lipoprotein cholesterol.

* The number of male graduates in nursing and nutrition was negligible ( 2 in nursing and 6 in nutrition).

a Individuals with non-health related degrees, other health-related degrees or participants with more than one degree are included in this category 
The LOWESS method was used because the dose-response relationship between two variables does not always follow a linear pattern. This method is more appropriate than a linear model to describe the dose-response pattern found in the data.

Self-reported height and current weight were used to calculate the body mass index (the weight in kilograms divided by the square of the height in meters) $\left(\mathrm{BMI}=\right.$ weight $(\mathrm{Kg}) /$ height $\left.(\mathrm{m})^{2}\right)$.

Smoking status was assessed using two variables. The first variable was the number of pack-years as the unit. A pack-year is a measure of the intensity and duration of smoking. For example, a person who has smoked a pack of cigarettes a day during 1 year is classified as smoking 1 pack-year. The second variable assessing smoking was present smoking status. Participants were classified as non-smokers, ex-smokers and current smokers with three categories for current smokers $(<10$ $\mathrm{cig} /$ day, 10-20 cig/day and $>20 \mathrm{cig} /$ day).

To quantify the volume of activity during leisure time, an activity metabolic equivalent (MET) index was computed by assigning a multiple of resting metabolic rate (MET score) to each activity. Metabolic equivalents represent the ratio of energy expended during each specific activity to resting metabolic rate and are independent of body weight. Time spent in each of the activities was multiplied by the MET score specific to each activity, and then summed over all activities obtaining a value of overall weekly MET-hours [24].

After bivariate analyses, a multiple regression model was fitted separately for men and women. The relative percentage of adherence to a MDP was used as the outcome. The potential predictors were age, gender, smoking status, body mass index, physical activity during leisure time, self-awareness of HDL-cholesterol levels and total cholesterol levels, previous diagnosis of hypertension, diabetes or hypercholesterolemia, cancer screening, perceived body size, television viewing, taking a nap, type of university degree completed in college and the highest attained educational level of each participant.

\section{Results}

The mean age was 39.9 years for men and 35.3 years for women. Self-reported body mass index was $25.2 \mathrm{Kg} \mathrm{m}^{-2}$ for men and $21.7 \mathrm{Kg} \mathrm{m}^{-2}$ for women. Intensity and duration of smoking was measured using the pack-year as the unit. The mean was 15.4 pack-years for men and 5 pack-years for women among smokers. The mean physical activity during leisure time was 26 METs-hour/week for men and 21.5 METs-hour/week for women. On average, men and women spent 10 hours a week viewing television. Men spent an average of nearly 2 hours taking a nap whereas women spent 1.7 hours a week. Ten percent of men and women spent more than 20 and 21 hours a week respectively viewing television and more than 5.3 hours a week taking a nap. Moreover, a substantial proportion of participants were living in Navarre $(30.2 \%$ of men and $42.1 \%$ of women) (data not shown).

After excluding participants with missing data or extreme values of total energy intake in the food frequency questionnaire, 3,847 subjects $(1,587$ men and 2,260 women) were included in the analyses to determine the adherence to a MDP.

Coefficients of variation were $26.8 \%$ and $23.3 \%$ for men and women respectively in the adherence to a MDP.

The distribution of the main characteristics of the sample across quintiles of the relative percentage of adherence to an "a priori" MDP is shown in Table 1 for men and in Table 2 for women.

Older, physically active and ex-smoker men were more likely to follow the MDP. Among women a similar trend was observed regarding age and physical activity during leisure time.

When we used the LOWESS non-parametric regression, we observed a positive association between age and the relative adherence to a MDP (i. e., younger participants exhibited a poorer compliance with the traditional Mediterranean diet). Whereas an almost perfect linear relationship was apparent for men, the linear association was seen only among those older than 35 years for women. This finding suggests that the adherence to the MDP only increases with age in women older than 35 years (Fig. 1).

Because smoking and body mass index are age-dependent variables, they were adjusted for age before using them in the LOWESS models. Failing to perform this adjustment would have led to confounding. The cumulative number of cigarettes smoked (as pack-years) adjusted for age was not associated with the relative percentage of adherence to a MDP in men, whereas there was a positive association in women (data not shown).

Body mass index adjusted for age showed a U-shaped relationship with the relative percentage of adherence to a MDP among men. There was no association for women (data not shown). Physical activity during leisure time (METs-hour/week) showed a positive association for both men and women with an almost linear pattern (Fig. 2). The number of hours spent taking a nap were positively associated with the adherence to a MDP in men, whereas the relationship was negative for women after 5 or more hours of napping per week (Fig. 3). Weekly hours viewing television were not associated with the relative percentage of adherence to a MDP (data not shown).

The results of the multivariate regression analysis regarding gender showed that the mean relative percentage of adherence to a MDP was higher among women than among men. The mean difference was $4.1 \%(95 \%$ 
Table 2 Distribution of sociodemographic and lifestyle variables across quintiles of the "a priori" defined MDP in women

\begin{tabular}{llllll}
\hline \multicolumn{5}{c}{ QUINTILE of the "a priori" defined MDP } \\
\cline { 2 - 6 } & Q1 & Q2 & Q3 & Q4 & Q5 \\
\hline Age (years) [mean (SD)] & $32.4(8.2)$ & $34.4(9.0)$ & $34.9(9.5)$ & $36.5(10.8)$ & $38.1(12.6)$ \\
Physical activity during leisure & $18.4(18.0)$ & $17.6(16.2)$ & $21.7(21.4)$ & $20.9(18.9)$ & $25.2(22.7)$ \\
time in METs-hour/week & & & & & \\
[mean (SD)] & & & & & \\
Self-awareness of HDL-c levels (\%) & 33.5 & 29.2 & 33.5 & 36.3 & 33.5 \\
Hours a week taking a nap & $2.1(2.7)$ & $2.0(2.6)$ & $2.0(2.5)$ & $1.9(2.2)$ & $2.0(2.7)$ \\
(siesta) [mean (SD)] & & & & & \\
Smoking (\%) & & & & & \\
$\quad$ Ex-smokers & 17.1 & 24.3 & 22.1 & 27.6 & 23.6 \\
$\quad$ Current smokers & 22.2 & 24.5 & 26.9 & 25.8 & 27.0 \\
University degree completed & & & & & \\
in college (\%) & & & & & \\
$\quad$ Medicine & 12.5 & 12.5 & 12.3 & 12.9 & 14.6 \\
$\quad$ Pharmacy & 15.0 & 12.0 & 13.2 & 9.5 & 12.2 \\
$\quad$ Biology & 6.4 & 7.2 & 7.2 & 9.2 & 5.2 \\
$\quad$ Nursing & 11.5 & 15.7 & 13.9 & 14.1 & 12.8 \\
$\quad$ Nutrition & 4.4 & 3.6 & 3.6 & 4.9 & 6.3 \\
$\quad$ Other degrees ${ }^{\mathrm{a}}$ & 50.2 & 49.0 & 49.8 & 49.4 & 48.9 \\
\hline
\end{tabular}

Q1-Q5 Quintiles values of adherence to the "a priori" defined MDP.

SD Standard Deviation

METs-hours/week Metabolic equivalents of energy expenditure in leisure time physical activities during one week.

HDLC High density lipoprotein cholesterol.

${ }^{a}$ Individuals with non-health related degrees, other health-related degrees or participants with more than one degree are included in this category
Men

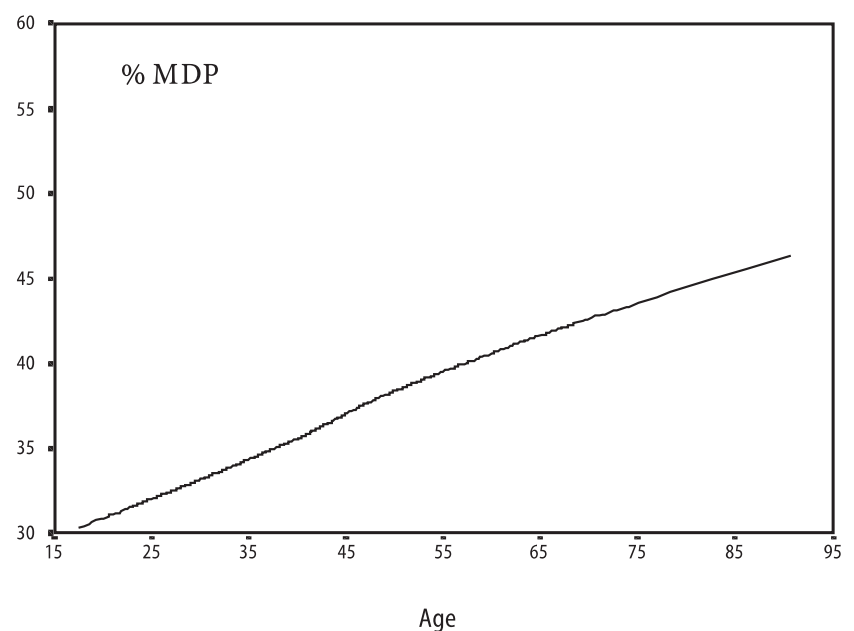

Women

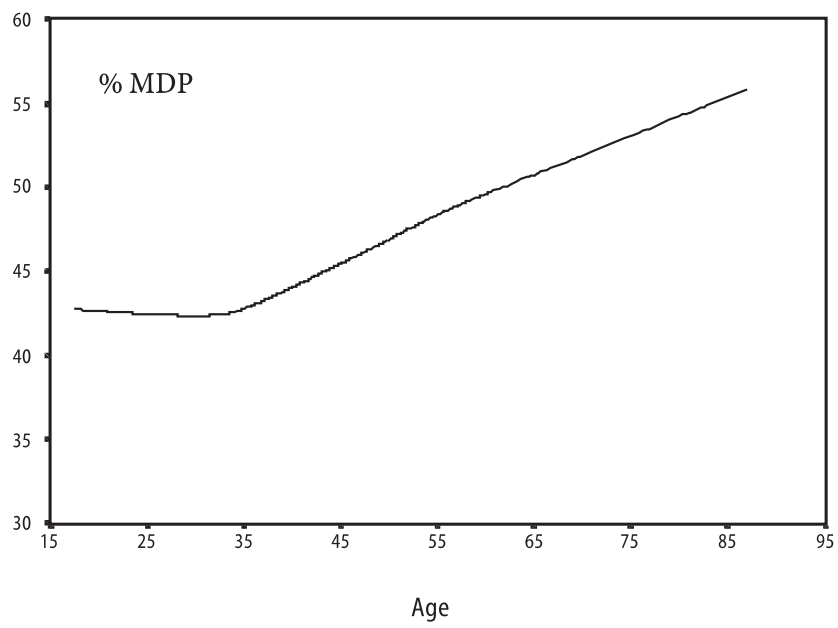

Fig. 1 Relationship between age (years) and relative adherence to a Mediterranean dietary pattern (\% MDP). (Locally Weighted Regression Scatterplot Smoothing)

Confidence Interval $(\mathrm{CI})=3.2 \%$ to $4.9 \%$ ) after adjusting for age, smoking status, body mass index, physical activity during leisure time, self-awareness of HDL-cholesterol levels and total cholesterol levels, previous diagnosis of hypertension, diabetes or hypercholesterolemia, screening of different cancers, perceived body size, television viewing, taking a nap, type of university degree completed in college and the highest attained educational level of each participant.

Subsequently, all analyses were done separately for men (Table 3) and for women (Table 4). The self-awareness of HDL-cholesterol levels was associated with a higher adherence to the pattern among men. The regression coefficient was $1.4(95 \% \mathrm{CI}=0.1$ to 2.8$)$. 
Men

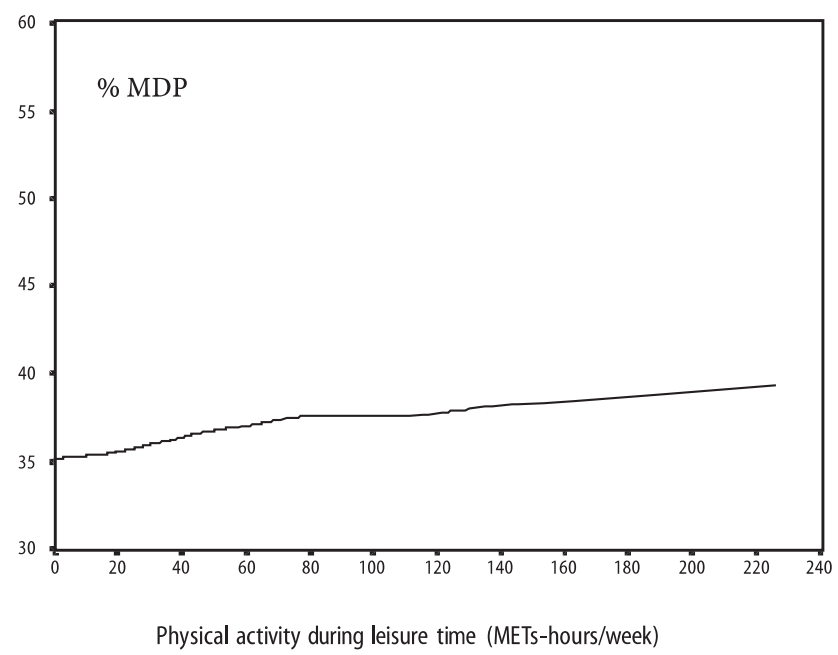

Women

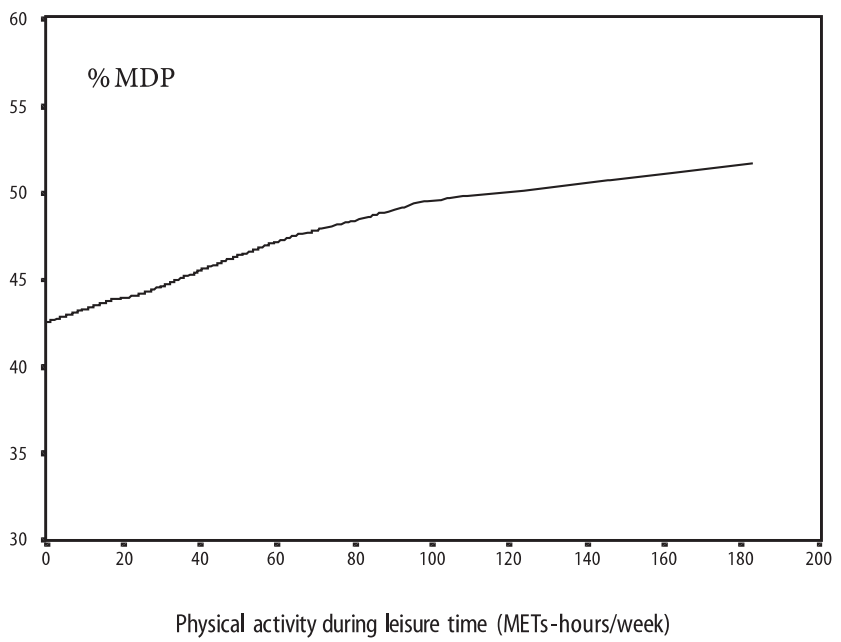

Fig. 2 Relationship between physical activity during leisure time (METs-hours/week) and relative adherence to a Mediterranean dietary pattern (\% MDP). (Locally Weighted Regression Scatterplot Smoothing)

Men

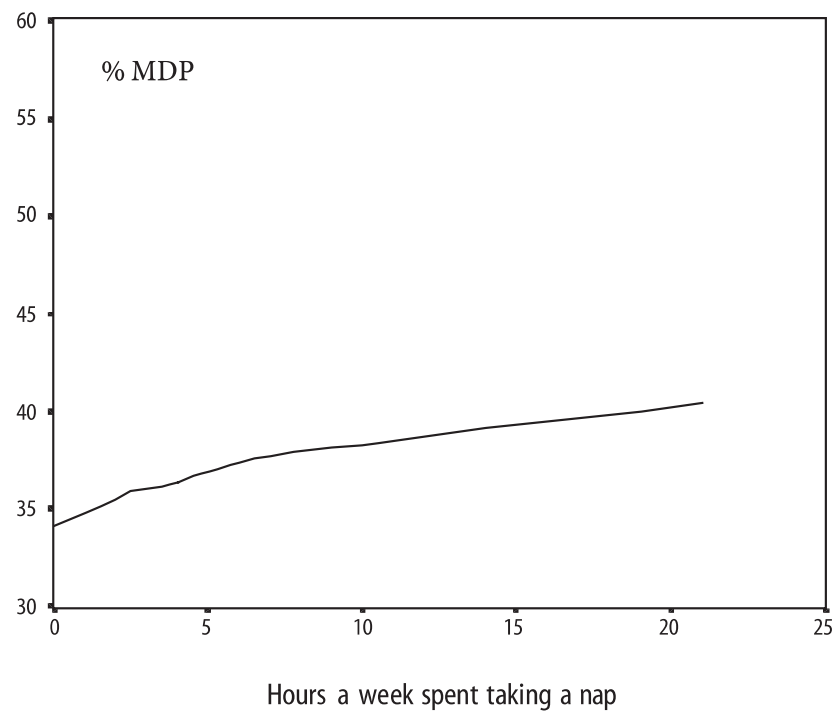

Women

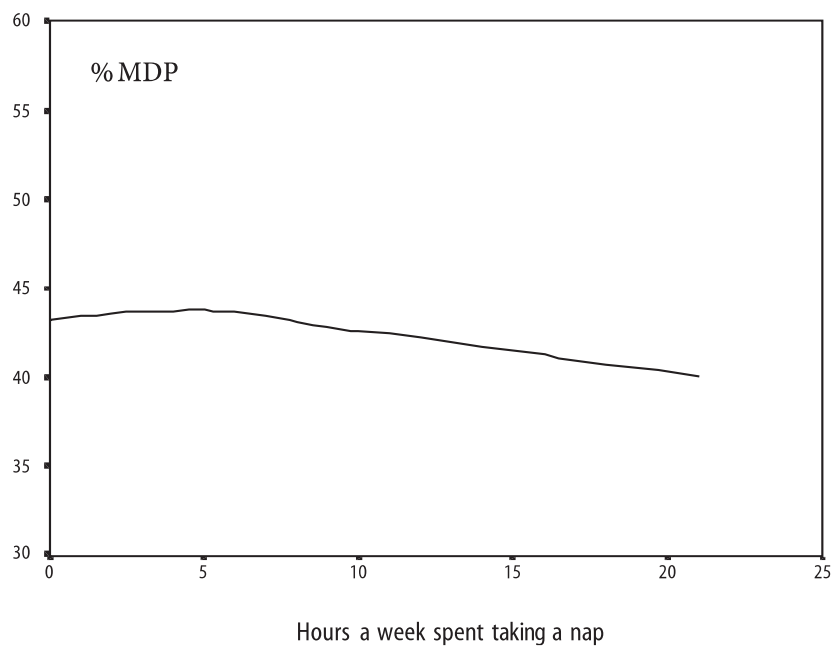

Fig. 3 Relationship between the hours a week spent on taking a nap and relative adherence to a Mediterranean dietary pattern (\% MDP). (Locally Weighted Regression Scatterplot Smoothing)

Hours a week spent on taking a nap were grouped into tertiles. Taking a nap was associated with a higher adherence to the MDP in men but not in women. For men, the regression coefficients were $1.4(95 \% \mathrm{CI}=0$ to $2.7)$ for the second tertile and $1.6(95 \% \mathrm{CI}=0.1$ to 3.1$)$ for the third tertile when they were compared with the first tertile.

Women who had a college degree in nutrition showed higher adherence to a MDP than women who had completed other college degrees. This association was not statistically significant among men because of the small number of males with a degree in nutrition.

Women who were ex-smokers or smokers of 10 to 20 cigarettes a day showed a higher and statistically significant adherence to a MDP $(p=0.025$ and $p=0.001$, respectively) than non-smokers. In the multivariate model we did not find a statistically significant association between smoking status and the percentage of adherence to the MDP among men. A significant positive association was found between age and physical activity during 
Table 3 Variables associated with the adherence to a Mediterranean dietary pattern (men). Linear multiple regression with the relative percentage of adherence to an "a priori" defined MDP as dependent variable
Table 4 Variables associated with the adherence to a Mediterranean dietary pattern (women). Linear multiple regression with the relative percentage of adherence to an "a priori" defined MDP as dependent variable

\begin{tabular}{|c|c|c|c|c|c|}
\hline & $\mathrm{n}$ & b univariate & b multivariate & $95 \% \mathrm{Cl}$ & $\mathrm{p}$ \\
\hline Age (years) & 1565 & $+0.27^{* *}$ & +0.25 & +0.18 to +0.32 & $<0.001$ \\
\hline $\begin{array}{l}\text { Physical activity during leisure } \\
\text { time in METs-hours/week }\end{array}$ & 1549 & $+0.03^{* *}$ & +0.03 & +0.01 to +0.06 & 0.01 \\
\hline \multicolumn{6}{|c|}{ Self-awareness of HDL-cholesterol levels } \\
\hline No & 1101 & 0 (ref.) & 0 (ref.) & & \\
\hline Yes & 485 & $+2.77^{* *}$ & +1.44 & +0.11 to +2.77 & 0.03 \\
\hline \multicolumn{6}{|l|}{ Hours a week taking nap (tertiles) } \\
\hline 0 (h/week) & 477 & 0 (ref.) & 0 (ref.) & & \\
\hline 3.5 (h/week) & 438 & $+2.14^{* *}$ & +1.37 & +0.02 to +2.72 & 0.05 \\
\hline 21 (h/week) & 361 & $+3.01^{* *}$ & +1.60 & +0.10 to +3.10 & 0.04 \\
\hline \multicolumn{6}{|l|}{ Smoking } \\
\hline Non-smokers & 731 & 0 (ref.) & 0 (ref.) & & \\
\hline Ex-smokers & 420 & $+2.91^{* *}$ & -0.23 & -1.74 to +1.27 & 0.76 \\
\hline Smokers $<10$ cig/day & 175 & $+1.84^{*}$ & 0.00 & -1.86 to +1.87 & 1.00 \\
\hline Smokers $10-20$ cig/day & 142 & +0.73 & +1.30 & -0.93 to +3.54 & 0.25 \\
\hline Smokers $>20$ cig/day & 51 & -2.58 & -2.90 & -7.28 to +1.48 & 0.19 \\
\hline \multicolumn{6}{|c|}{ University degree completed in college* } \\
\hline Medicine & 277 & 0 (ref.) & 0 (ref.) & & \\
\hline Pharmacy & 68 & -2.08 & -0.16 & -3.05 to +2.72 & 0.91 \\
\hline Biological Science & 79 & -2.04 & -2.09 & -4.81 to +0.62 & 0.13 \\
\hline Other degrees ${ }^{\mathrm{a}}$ & 948 & $-1.59^{*}$ & -0.23 & -1.79 to +1.32 & 0.77 \\
\hline
\end{tabular}

$b$ Regression coefficients in a multiple regression model.

${ }^{*} \mathrm{p}<0.05 ;{ }^{* *} \mathrm{p}<0.01$

A positive sign in the coefficients indicates a greater adherence to a Mediterranean pattern.

METs-hours/week Metabolic equivalents of energy expenditure in leisure time physical activities during one week; HDLc High density lipoprotein cholesterol.

* The number of male graduates in nursing and nutrition was negligible ( 2 in nursing and 6 in nutrition).

${ }^{a}$ Individuals with non-health related degrees, other health-related degrees or participants with more than one degree are included in this category

\begin{tabular}{|c|c|c|c|c|c|}
\hline & $\mathrm{n}$ & b univariate & b multivariate & $95 \% \mathrm{Cl}$ & $\mathrm{p}$ \\
\hline Age (years) & 2226 & $+0.21^{* *}$ & +0.20 & +0.13 to +0.27 & $<0.001$ \\
\hline $\begin{array}{l}\text { Physical activity during leisure } \\
\text { time in METs-hours/week }\end{array}$ & 2201 & $+0.09^{* *}$ & +0.08 & +0.05 to +0.10 & $<0.001$ \\
\hline \multicolumn{6}{|c|}{ Self-awareness of HDL-cholesterol levels } \\
\hline No & 1508 & 0 (ref.) & 0 (ref.) & & \\
\hline Yes & 749 & +0.68 & -0.23 & -1.53 to +1.07 & 0.73 \\
\hline \multicolumn{6}{|l|}{ Hours a week taking nap (tertiles) } \\
\hline 0 (h/week) & 814 & 0 (ref.) & 0 (ref.) & & \\
\hline 2.5 (h/week) & 414 & -0.45 & +0.07 & -1.47 to +1.61 & 0.93 \\
\hline 21 (h/week) & 611 & +0.30 & -0.19 & -1.59 to +1.21 & 0.79 \\
\hline \multicolumn{6}{|l|}{ Smoking } \\
\hline Non-smokers & 1136 & 0 (ref.) & 0 (ref.) & & \\
\hline Ex-smokers & 503 & $+1.32^{*}$ & +1.76 & +0.22 to +3.29 & 0.03 \\
\hline Smokers < 10 cig/day & 369 & +0.56 & +1.62 & -0.06 to +3.29 & 0.06 \\
\hline Smokers 10-20 cig/day & 147 & +1.77 & +4.66 & +2.03 to +7.29 & 0.001 \\
\hline Smokers > 20 cig/day & 38 & -0.37 & +0.16 & -4.83 to +5.16 & 0.95 \\
\hline \multicolumn{6}{|c|}{ University degree completed in college } \\
\hline Medicine & 263 & 0 (ref.) & 0 (ref.) & & \\
\hline Pharmacy & 252 & -0.74 & +0.65 & -1.77 to +3.06 & 0.60 \\
\hline Biological Science & 144 & -0.33 & -0.07 & -2.87 to +2.73 & 0.96 \\
\hline Nursing & 277 & -0.19 & -2.34 & -6.04 to +1.37 & 0.22 \\
\hline Nutrition & 92 & +1.27 & +3.89 & +0.97 to +6.80 & 0.01 \\
\hline Other degrees ${ }^{\mathrm{a}}$ & 1007 & -0.26 & +0.92 & -1.00 to +2.83 & 0.35 \\
\hline
\end{tabular}

$b$ Regression coefficients in a multiple regression model.

${ }^{*} p<0.05 ;{ }^{* *} p<0.01$

A positive sign in the coefficients indicates a greater adherence to a Mediterranean pattern.

METs-hours/week Metabolic equivalents of energy expenditure in leisure time physical activities during one week; HDLc High density lipoprotein cholesterol.

a Individuals with non-health related degrees, other health-related degrees or participants with more than one degree are included in this category 
leisure time and the adherence to a MDP for both men and women.

\section{Discussion}

The results of our analysis showed an association between some life-style characteristics and the adherence to a global MDP. There are studies that have associated the socioeconomic characteristics and life-styles of the population with the adherence to several patterns [25, 26] but to our knowledge this is the first time that the factors associated with the adherence to a MDP have been analyzed in a large population of free living individuals.

We found that age was associated with a higher adherence to the MDP. Thus, a departure of young people from the traditional Mediterranean diet was evident. Previous studies have suggested this process of giving up the traditional MDP among younger people [27], but no convinced evidence was collected.

Similarly, in our analysis we found that physical activity during leisure-time was associated with an increased adherence to the MDP in both men and women. Therefore, our data suggest that the beneficial effect attributed to the MDP against CHD and other related diseases [5-9] could be due not only to diet, but also in part to a more active life-style during leisure time of those who follow the traditional Mediterranean diet [28].

On the other hand, taking a nap (siesta) is a typical characteristic of the Mediterranean life-style that has been hypothesized as a beneficial factor against CHD [29], but not all evidence is consistent [30]. When we analyzed the habit of taking a nap, we found a strong association between this typical Mediterranean habit and the adherence to a MDP but this association was only present in men. The discordant findings between the Greek study and the recently conducted study in Costa Rica might be explained because of residual confounding given the positive association between the adherence to the MDP and siesta.

Thus, we could speak about the Mediterranean lifestyle instead of the MDP and include a higher level of physical activity as one aspect associated with the MDP which can be protective against different diseases. This supports the hypothesis of a clustering of variables related to a healthy life-style because those who followed a MDP, usually considered as a healthy pattern, were more active.

Contrar to previous investigations, we did not find an association between smoking and the adherence to a MDP. Martínez-González et al. found an association between an unhealthy dietary pattern and smoking in a typical Mediterranean population [31]. In the same way, a study based on a representative sample of Catalonia (a Spanish region) found a greater intake of fats, mainly saturated fatty acids and lower consumption of fruit, nuts and fiber among smokers [32]. Our subjects belong to a population stratum with a high educational level. On average, higher socioeconomic level, measured as educational level, has been associated with the adherence to a healthier dietary pattern [33]. Perhaps, there is a prevalent healthy dietary pattern among our participants independently of their smoking status and it is less likely to find in them the association between smoking and less healthy dietary habits.

There are several limitations in our analysis. One limitation could be due to self-reported measurements for nutrient intake and food item consumption. We used a semi-quantitative food frequency questionnaire as the nutritional measurement instrument to obtain the MDP. People might overestimate the consumption of healthyconsidered nutrients and food items like vegetables, fruit or cereals, typical components of the MDP and to underestimate the consumption of unhealthy-considered nutrients and food items like fats $[34,35]$. A recall bias may have happened. Participants were asked about consumption during the past year. Nevertheless, these potential problems would bias the association toward the null value [36]. Moreover, participants answered a large questionnaire and were specially motivated to answer correctly the questions without causing misclassification. Therefore, the use of a validated food-frequency questionnaire assures the suitability of the responses.

Finally, we used participants belonging to a high educational level. Thus, they can not be considered as a representative sample from the general Spanish or Mediterranean population. However, this cohort study has been designed in order to ascertain the factors (including nutritional factors) associated with the incidence of several diseases. The important issue in this setting is to ensure a fair degree of between-person variability in nutrient intake rather than to ensure the representativeness of the sample [36]. Moreover, since highly educated people exert an exemplary role on less educated people, their departure from the traditional Mediterranean diet will also be eventually adopted by other sectors of the Spanish population. In addition, the use of a highly educated population ensures and increases the validity of the methods for dietary assessment we have used.

In conclusion, in spite of the above mentioned limitations, our findings suggest a progressive departure from the traditional MDP in the younger subjects of the SUN cohort which is being developed in a Mediterranean area. Moreover, the subjects of this cohort who belong to a more active life-style are more likely to follow the MDP.

Acknowledgments The Department of Health of the Navarre Regional Government and FIS (Fondo de Investigaciones Sanitarias) of the Spanish Ministry of Health are gratefully acknowledged for support of this study. 


\section{References}

1. Keys A, Grande F (1957) Dietary fat and serum cholesterol. Am J Public Health 47:1520-1530

2. Trichopoulou A, Lagiou P (1997) Healthy traditional Mediterranean diet: an expression of culture, history, and lifestyle. Nutr Rev 11:383-389

3. Willett WC, Sacks F, Trichopoulou A, Drescher G, Ferro-Luzzi A, Helsing E, Trichopoulos D (1995) Mediterranean diet pyramid: a cultural model for healthy eating. Am J Clin Nutr 61: 1402S-1406S

4. Hu FB, Rimm EB, Stampfer MJ, Ascherio A, Spiegelman D, Willett WC (2000) Prospective study of major dietary patterns and risk of coronary heart disease in men. Am J Clin Nutr 72:912-921

5. Kris-Etherton P, Eckel RH, Howard BV, St Jeor S, Bazarre TL (2001) Lyon Diet Heart Study. Benefits of a Mediterranean-style, national cholesterol education program/American Heart Association step I dietary pattern on cardiovascular disease. Circulation 103: 1823-1825

6. De Lorgeril M, Salen P, Martín JL, Monjaud I, Delaye J, Mamelle N (1999) Mediterranean diet, traditional risk factors, and the rate of cardiovascular complications after myocardial infarction: final report of the Lyon Diet Heart Study. Circulation 99:779-785

7. Ryan $M, M c$ Inerney $D$, Owens $D$, Collins P, Johnson A, Tomkin GH (2000) Diabetes and the Mediterranean diet: beneficial effects of oleic acid. QJM 93: 85-91

8. Ferrara LA, Raimondi S, d'Episcopo L, Guilda L, Dello Russo A, Marotta T (2000) Olive oil and reduced need for antihypertensive medications. Arch Intern Med 160:837-842

9. Joshipura KJ, Ascherio A, Manson JA, Stampfer MJ, Rimm EB, Speizer FE, Hennekens CH, Spiegelman D, Willett WC (1999) Fruit and vegetable intake in relation to risk of ischemic stroke. JAMA 282:1233-1239

10. Trichopoulou A, Georgiou E, Bassiakos Y, Lipworth L, Lagiou P, Proukakis C, Trichopoulos D (1997) Energy intake and monounsaturated fat in relation to bone mineral density among women and men in Greece. Prev Med 26: 395-400

11. Willett WC, Trichopoulos D (1996) Nutrition and cancer: a summary of the evidence. Cancer Causes Control 7: 178-180

12. Martin Moreno JM, Willett WC, Gorgojo L, Banegas JR, Rodríguez-Artalejo $\mathrm{F}$, Fernández-Rodríguez JC, Maisonneuve P, Boyle P (1994) Dietary fat, olive oil intake and breast cancer risk. Int J Cancer 58:774-780
13. Martin-Moreno JM, Boyle P, Gorgojo L, Maisonneuve P, Fernandez-Rodriguez JC, Salvini S, Willett WC (1993) Development and validation of a food frequency questionnaire in Spain. Int J Epidemiol 22:512-519

14. Willett WC, Sampson L, Stampfer MJ, Rosner B, Bain C, Witschi J, Hennekens CH, Speizer FE (1985) Reproducibility and validity of a semiquantitative food frequency questionnaire. Am J Epidemiol 122:51-65

15. Mataix J (1998) Tabla de composición de alimentos españoles. Universidad de Granada, Granada

16. Moreiras O (1995) Tablas de composición de alimentos. Pirámide, SA, Madrid

17. Trichopoulou A, Kouris-Blazos A, Wahlqvist ML, Gnardellis C, Lagiou P, Polychronopoulos E, Vassilakou T, Lipworth L, Trichopoulos D (1995) Diet and overall survival in elderly people. BMJ 311:1457-1460

18. Kouris-Blazos A, Gnardellis C, Wahlqvist ML Trichopoulos D, Lukito W, Trichopoulou A (1999) Are the advantages of the Mediterranean diet transferable to other populations? A cohort study in Melbourne, Australia. Br J Nutr 82:57-61

19. Lasheras C, Fernandez S, Patterson AM (2000) Mediterranean diet and age with respect to overall survival in institutionalized, nonsmoking elderly people. Am J Clin Nutr 71:987-992

20. Willett W, Stampfer MJ (1998) Implications of total energy intake for epidemiologic analysis. In: Willett W (ed) Nutritional Epidemiology. Oxford University Press, New York, pp 273-301

21. Stampfer MJ, Colditz GA, Willett WC, Speizer FE, Hennekens CH (1988) A prospective study of moderate alcohol consumption and the risk of coronary disease and stroke in women. $\mathrm{N}$ Engl J Med 319:267-273

22. Rimm EB, Giovannucci EL, Willett WC, Colditz GA, Ascherio A, Rosner B, Stampfer MJ (1991) Prospective study of alcohol consumption and risk of coronary disease in men. Lancet 338: 464-468

23. Cleveland WS (1979) Robust locally weighted regression and smoothing scatter-plots. J Am Stat Assoc 74: 829-836

24. Ainsworth BE, Haskell WL, Whitt MC, Irwin ML, Swartz AM, Strath SJ, et al. (2000) Compendium of physical activities: an update of activity codes and MET intensities. Med Sci Sports Exerc 32:498S-504S
25. Whichelow MJ, Prevost AT (1996) Dietary patterns and their associations with demographic, lifestyle and health variables in a random sample of British adults. Br J Nutr 76:17-30

26. Kant AK, Thompson FE (1997) Measures of overall diet quality from a food frequency questionnaire: National Health Interview Survey, 1992. Nutr Res 17:1443-1456

27. Serra-Majem L, La Veccia C, Ribas Bara L, Prieto Ramos F, Luccini F, Ramon JM, Salleras L (1993) Changes in diet and mortality from selected cancers in Southern Mediterranean countries, 1960-1989. Eur J Clin Nutr 47:25S-34S

28. US Preventive Services Task Force (1996) Counseling to promote physical activity. In: US Preventive Services Task Force. Guide to Clinical Preventive Services. Williams and Wilkins, Baltimore, pp 611-624

29. Kalandidi A, Tzonou A, Toupadaki N, Lan S, Koutis C, Drogari P, Notara V, Hsieh C, Toutouzas P, Trichopoulos D (1992) A case-control study of coronary heart disease in Athens, Greece. Int J Epidemiol 21:1074-1078

30. Campos H, Siles X (2000) Siesta and the risk of coronary heart disease: results from a population-based, case-control study in Costa Rica. Int J Epidemiol 29:429-437

31. Martínez-González MA, Pérez-Gutiérrez R, Martínez-González J, GarcíaMartín M, Bueno-Cabanillas A (1997) Dietary intake of some food items in smokers and non-smokers in a Mediterranean population. Eur J Public Health 7:40-44

32. Serra-Majem L, Román Viñas B, Ribas Barba L, Ramón JM, Lloveras G (2001) Food consumption and nutrient intake in relation to smoking. Med Clin (Barc) 116:129-132

33. Fraser GE, Welch A, Luben R, Bingham SA, Day NE (2000) The effect of age, sex, and education on food consumption of a middle-aged English Cohort-EPIC in East Anglia. Prev Med 30:26-34

34. Martínez-González MA, López-Azpiazu I, Kearney J, Kearney M, Gibney M, Martínez JA (1998) Definition of healthy eating in the Spanish adult population: a national sample in a panEuropean survey. Public Health 112: 95-101

35. Macdiarmid J, Blundell J (1998) Assessing dietary intake: who, what and why of under-reporting. Nutr Res Rev 11: 231-253

36. Rothman KJ, Greenland S (1998) Precision and validity in epidemiologic studies. In: Rothman KJ, Greenland S (eds) Modern Epidemiology. LippincotRaven, Philadelphia, pp 115-134 